\title{
Contemporary work: its meanings and demands
}

Patricia Findlay and Paul Thompson, Industrial Relations Journal, In Press.

The questions that social scientists ask concerning the meaning of work can be initially separated into what work wants from us and what we want from it. The former relies on identifying recurrent objective trends in how we are managed and rewarded, the kinds of jobs that are being created and the challenges they do or do not offer, and how secure or precarious they are. The latter tends to focus on subjective measures of satisfaction, (dis)engagement, attachment and identity. Both are highly contested in academic research and public discourse.

Not so long ago there was considerable optimism about emergent work trends in post-industrial service or knowledge economies, with its symbolic analysts, self-programmable workers, creative class and immaterial labour. At the same time, we hear repeatedly about the growth of zero hour contracts, stagnant or declining real wages, rising levels of work stress and punitive performance regimes. Tech giants such as Amazon are embarrassed by exposures of 'bruising' work cultures at its offices and warehouses. Meanwhile, pessimistic discourses of a 'crisis of work' are predicated not just on gloomy forecast about a new wave of automation, but of a generalised precariousness and proliferation of 'bullshit jobs' (Srnicek and Williams 2015; Mason 2015).

What about the subjective side? As we illustrate in a later section, there seems to be some support for prognoses in reports of falling employee engagement levels and rising cynicism at work. However, survey research still picks up high levels of employee self-reported satisfaction with their work. For all the talk of the end of work society or identity, employees, even in routine jobs, draw satisfaction from aspects of their work such as social interaction with customers and workmates (Kalleberg 2009; Doherty 2009). Female workers' satisfaction levels are higher than men's despite unequal treatment (Bolton and Houlihan 2009), with Hochschild (1997) reporting that some employees, especially women, are choosing longer hours because they 'love their work'. 
How do we explain these apparent paradoxes? Research questions are not random. We have to choose what, who and where to study. One distorting factor is that social theory frames our understanding of work trends, yet such theorising frequently gains prominence through the promotion of novelty or binary opposition between the old or new rather than more grounded, qualified accounts. One aspect of this is the identification of 'exemplary' industries - in the recent period web design or games - that supposedly lead economic and workplace change. There are indeed some very interesting developments, but there is a certain amount of digital delusion in the view that they tell us much about typical trends. Though games is a multi-billion dollar industry, it employs fewer than 10,000 people in development in the UK. Glasgow City Council alone has 20,000 employees. Supermarkets and care services, with their mostly female, low paid workforces, are amongst the largest job growth sectors in many countries. Whilst it is certainly possible to find research articles on them (e.g. Hebson et al 2015), they are seldom the focal point for wider theory building. Despite all the hype about globalization, work trends are still seen overwhelmingly through the prism of certain industries in post-industrial economies. Factory work has been rendered almost invisible in this process, yet China - the engine of the world economy - has ever larger factories based on standardized mass production. Such trends cannot be parked as 'somewhere else' given that many of those products are central to the value chains of the most advanced US and European companies (Smith and Liu 2016).

Questions are also affected by how we study. There is a traditional divide between quantitative and qualitative researchers. In many countries, including the UK and Australia, there are long established national surveys of work and employment trends. Though survey questions do have limitations with respect to who is reporting and what they are reporting on, these surveys are an indispensable source of information on key issues and trends, identifying patterns over time, even if these need further interpretation and explanation. There is a strong qualitative case study tradition in both countries, influenced in part by labour process perspectives. Though there is a danger of cherry 
picking voices that confirm prior preferences, trends can still be identified across bodies of work that are more attentive to context and agency.

Finally, the most obvious explanation for paradoxical claims is that we are simply looking at different ends of the telescope. In other words, that positive experiences and attachments are associated with jobs higher up the occupational ladder, whilst the reverse is true for those on the receiving end of punitive or precarious outcomes. It would be counter-intuitive if this were not to some extent true. However, employee experiences are strongly linked to expectation and if, for example, professional employees suffer a decline in influence, this will be felt negatively even if professionals are still more influential than other employees. It is our contention that there are a set of overlapping dynamics within post-industrial economies that mean that contradictory trends run across as well as between groups. The main section of the article examines five core issues (in)security, effort and intensity, performance management and monitoring, work/life boundaries and (dis)engagement - to build up a complex picture of these trends. Given the range of issues that could have been selected, why these five? It seems to us that Green's (2006) term 'demanding work' best captures the underlying dynamic of contemporary trends and these five issues are at the heart of those issues and what makes them contentious and sometimes misunderstood. These issues allow us to focus not only on those changing demands, but on the meanings and demands placed by workers. Even with a focus on a selection of overlapping issues there is a vast array of potential data, so we restrict our empirical observations primarily to the UK and Australia.

\section{(In)security}

Security at work is an important aspiration for workers and their families and underpins stable economies and societies (Streeck 2008). Yet in recent years, insecurity or precarity has dominated debates on work, drawing attention to the rise and costs of precarious employment (Standing 2011). Some of this debate has lacked perspective and has exaggerated the reach and cohesiveness of precarity (everything from the self-employed, agency and part-time workers and service workers to 
permanent employees unhappy with their promotion prospects), while offering scant evidence to support claims of a transformation from regular work, fixed workplaces and working time (Conley 2012).

Yet something is undoubtedly going on in relation to precarious and insecure work - notwithstanding a lack consensus as to its definition, nature and extent. National surveys (WERS/AWRS)' indicate that around $20 \%$ of UK and Australian workers are not in full-time regular employment. Flexible employment rose by 6\% in Europe over 1980-2011, while non-standard working has accounted for all UK net jobs growth since 1995 (OECD 2015). While a positive case can be made for some forms of labour market flexibility that can benefit employers as well as distinctive groups such as high skilled 'itinerant' workers, the experience of much non-standard work in Western economies is largely negative as the burden of risk and uncertainty falls disproportionately on workers (Green 2006; Kalleberg 2009). The evidence is clear in some respects: we know that non-standard working is more contractually insecure and offers less access to paid leave, sick pay or maternity as well as training opportunities and career development (ONS 2014; Dekker and van der Veen 2015; Knox 2015). In contrast, job security remains the most valued aspect of work in many countries (Munoz de Bustillo et al 2011).

Beyond this, the challenge is to capture trends and variation over time, place and context, and attention needs to shift from the overall proportion of 'insecure' work to experiences within particular categories. For example, self-employment has been rising in the UK and Australia and in part this reflects employers' strategies to evade the legal or contractual protections associated with employee status rather than the choices of workers. While sham or bogus self-employment is prohibited in both countries, there are huge challenges in policing this (Philpott 2012). In the UK, self-employment is associated with insecurity and with low pay (ONS 2014). Similarly, temporary agency workers in Australia are not only less satisfied with job security than their counterparts job 
security but also in relation to skill utilization and development, pay, autonomy and influence at work (Hall 2006).

Of course, national surveys highlight that around four fifths of employees in both countries are in permanent employment, with average job tenure having risen slightly in the UK while falling in Australia, albeit with significant variations by age and gender. Yet this fact doesn't preclude worsening insecurity for permanent workers - both standard and non-standard employees may become more insecure while maintaining a significant gap between them (Carre et al 2012). This takes us back to the need to research insecurity in context for all categories of workers. There is increasing evidence that we need to look beyond contractual arrangements and pay more attention labour process or job status insecurity, that is, anxiety '... about the threat of loss of valued features of the job' (Gallie et al 2016: 2). Drawing on longitudinal UK data, these authors report that developments in management practice, frequent organisational change, increasing performance expectations, closer monitoring and stronger sanctions for underperformance can generate anxiety about valued job features. Controlling for personality characteristics, they note that job status insecurity has increased, that as many as $38 \%$ of their sample exhibited at least one form of job status insecurity, and that anxiety over pay and having less say in the job were most prevalent. Indeed, high levels of anxiety were more prevalent with respect to job status than job tenure insecurity. Those in lower class/occupational positions had significantly higher job status insecurity, presumably as the costs of internal flexibility fell most heavily on those at the bottom, but every occupational group exhibited job status anxiety. Such developments may help to explain the increase in perceived insecurity in the UK over the period of global financial crisis, particularly in the public sector, as successive CIPD employee outlook surveys illustrate.

\section{Effort and intensity}

Time and circumstances change, but effort remains central to understanding what work demands from us. Rising work intensity has been a consistent and predominant theme of recent workplace 
research. In popular and academic discourse this tends to break down into working longer and working harder. Presenteeism and a long hours culture may not be universal, but it is an issue for employees in some sectors. WERS2011 reported that 35\% of workers worked from 40-48 hours per week with $11 \%$ working even longer hours. Moreover, $41 \%$ of respondents agreed that people who want to progress in their workplace usually have to put in long hours, with managers and professionals particularly likely to agree. Almost a third - mostly male - Australian employees work more than 45 hours. There is an interesting potential twist here, however. The questions do not specify where and how the 'long' hours take place. As Pocock et al (2012) argue, these individuals may take work home or don't take annual leave. They also report that most of those working long hours would like to work less. At the same time, we know that in both countries there is a significant minority in the ranks of part-time and casual workers who feel under-employed and who would like more hours.

As for working harder, an increase in 'discretionary effort' and 'working smarter not harder' were mantras in the promotion of high performance work systems. The extent to which additional effort has been discretionary is open to question. 'More work' and 'less pay' were the most common changes resulting from the recession reported by WERS2011 respondents. More recently, in a survey of 7400 UK workers, most said that productivity gains were secured through job cuts or faster work pace (Dromey 2016), while Felstead, Gallie, Green and Inanc (2013) report a rise in work intensification in the UK since 2001. A further strand of argument on work intensification is the claim from some UK academics that a new form of lean working is becoming characteristic of a growing number of public and private services. Lean production has previously been associated with Japanese management techniques to -improve quality and efficiency with fewer resources in manufacturing. More recently there has been moves to extend the model into new areas, including in the UK public sector and the evidence is persuasive for its negative effects on job quality and intensification in the civil service (Carter et al 2011). However, doubts over the effectiveness and 
sustainability of lean initiatives as well as resistance from employees has been raised elsewhere, for example in the health service (McCann et al 2015).

Using British and Australian data, Green uses the term 'demanding work' to refer to the spread of teamworking, multi-tasking and performance-related pay. Such work restructuring and reorganisation is far from paradigm break claims, but they represent managerial attempts to harness more aspects of labour power and access tacit knowledge and skills (Thompson 2013). Or, as McGovern et al put it, 'sustained physical, emotional and mental effort' (2007:127). The sources of such demands and subsequent work pressures are variable. Green identifies technological influences as a key factor, but one could equally point to targets and punitive performance regimes (the financial sector) or bureaucratic and audit burdens (in health and education). The point is that more demanding work is seldom a cohesive package affecting all sectors or in the same way. It also generates ambivalent responses from labour. Whilst there are widespread concerns about the previously identified 'more for less' trend, there is also evidence that employees welcome more challenging and involving work (Gallie et al 2016). Indeed, this can be seen alongside strong evidence of complaints by other employees of skill under-utilisation that is rooted, not in weakness of labour supply, but in demand, especially from fast growing low wage sectors such as hospitality and retail (Wright and Sissons 2012; Buchanan et al 2010).

\section{Performance monitoring and management}

Employee performance is always managed, albeit through a variety of control strategies shaped by market, regulatory, organisational, technological, labour supply and labour value considerations. Converging computer and telecommunications technologies has offered new possibilities for monitoring employee performance (Findlay and McKinlay 2003), with more recent emphasis on people analytics and 'smart' metrics. As well as the conventional focus on formalised performance management (PM), arguments for accountability to consumers and citizens also drive other forms of measurement and metrics, especially in the public sector. Taken together, these trends create a new 
context in which employee performance can be monitored, measured and compared in more intensive and enhanced ways. Some surveys suggest that PM is becoming ubiquitous. In both the UK and Australia surveys indicate that formal performance assessment has risen substantially. WERS2011 data for the UK establishes that PM for non-managerial workers rose from $43 \%$ in 2004 to $70 \%$ in 2011 . AWRS2015 data shows a similar rise in performance development planning and review for individual employees from $61 \%$ in 1995 to $77 \%$ of enterprises.

As with other issues, aggregate statistics hide interesting variation and unevenness. There is evidence of churn in the adoption of PM. In Australia more than $37 \%$ of the establishments using PM either adopted or abandoned it between 1990 and 1995, reflecting ' ... more than a simple movement towards formalization' (Brown et al, 2005:674). Similarly for the UK, CIPD (2015) report a decline from $65 \%$ to $49 \%$ in the number of organisations operating performance-related reward, incentive or recognition schemes, driven by lower use in the private sector. There are also significant data gaps and limitations on issues such as the relative use of quantitative versus normative/behavioural targets or on the processes for standardising or calibrating employee ratings. Interestingly, there isn't much robust evidence that formalised PM improves performance or productivity (Nankervis et al 2012). There is, however, extensive evidence on problems in its implementation. As one HR manager noted insightfully, "No one knew how the ratings were applied. Around four in five said they didn't understand the ratings process ... and I think the one in five may have been making it up" (Jacobs 2016). Implementation is also likely to be constrained by employee scepticism or resistance: $37 \%$ of UK employees see appraisals as a waste of time that does not develop their careers (Newcombe 2012), with over 30\% believing PM at their organisation is unfair (CIPD 2014). Indeed, in recent years a number of large organisations have publicly abandoned annual reviews and performance ratings (Rock and Jones 2015).

Much of the mainstream literature on performance has been dominated by a largely positivist occupational psychology perspective that has been heavy on measurement and its supposed 
accuracy and light on context and explanation. Recently, a smaller body of critical sociological scholarship on PM has emerged which gives important insights into political and economic context and to the nature of PM in specific organisations and sectors (Laaser 2016, Taylor 2013). Largely case study based and informed by labour process and critical management studies perspectives, these studies are well placed to illuminate how employees experience monitoring and measurement and have highlighted the dysfunctional and punitive nature of target-driven PM. Yet this literature by its nature lacks breadth, and does not adequately engage with the mainstream research, some of which recognises and addresses critically the legitimacy and effectiveness of contemporary developments (Budworth and Mann 2011; McKenna, Richardson and Manroop 2011). Significantly, this more critical research is silent on existing data suggesting any employee support for, or positive experience of, PM.

More fruitful inquiry might attempt to integrate insights from both critical and wider psychological/HR scholarship. Managing performance is, arguably, the core concern of management which in turn impacts significantly on the nature and experience of work. Workers have a legitimate interest in how their performance is managed, but also in the nature of that performance, given that doing, and being able to do, a good job links closely to intrinsic job quality. Moreover, PM encompasses a broad terrain of practices at different levels - individual-level performance measures may impact differently on workers than organisational level measures (for example, waiting time targets in health or league tables for schools). The complexities of measuring and managing individual and organisational performance and how this impacts on the design, operation and experience of PM systems poses complex research challenges, particularly in linking the employee, firm and sectoral level.

\section{Work/life boundaries}

The traditional emphasis on work-life balance (WLB) has been rightly criticised for its narrow and managerialist basis. However, a wider focus on shifting work-life boundaries has merit in picking up 
on some key trends. The 'balance' orientation continues in policy and academic discussion around aspects of flexible working, boosted by similar 'right to request' legislation in Australia and the UK. A variety of surveys provide evidence of coverage, take-up and attitudes. For Australia, 'the flexibility to balance work and non-work commitments' was the highest ranked factor in job satisfaction in AWRS, though $11 \%$ higher among women than men. The vast majority of workplaces are offering at least one form of time-based flexibility amongst a range of practices from part-time working, job share, flexitime, annualised hours and regular homeworking. However, coverage is patchy WERS2011 reveals the proportion of establishments using reduced hours (56\%), flexitime (34\%), homeworking (30\%), compressed hours (19\%), job sharing $(17 \%)$ and term-time only $(16 \%)$. These were not necessarily available to all employees and does not necessarily indicate either 'real' availability or actual take-up. In the UK the Fourth WLB Employer survey (BIS 2014) showed differences of $13 \%$ to $29 \%$ in employer and employee perceptions of availability of various WLB practices.

Australian studies of the right to request flexible working also indicate that whilst most requests are agreed, informal workplace cultures and gendered expectations continue to result in 'work-life interference' (Skinner and Pocock 2011). For example, there is a significant group of 'discontented non-requesters' who would like more flexibility but 'the nature of their job makes asking for change a waste of time' (Skinner and Pocock 2011:78). In the UK, 25\% of employees disagreed that they achieve the right WLB (CIPD 2015). Also for the UK, Angrave and Charlwood (2015) argue that it is not long hours per se that are the problem for such 'interference', but negative outcomes in subjective well-being are most associated with mismatches between preferred and actual hours. Whilst this is a valuable observation, it does raise the issue that work-life research needs to be more holistic and examine boundary changes across different domains. In other words, if there is a time squeeze, we need to examine not just hours worked, but the elasticity of some forms of contemporary work and their range of gendered impacts on the household (Pocock et al 2012). Traditional literatures have referred to this as job-to-home spillover and whilst far from universal 
across or even within all sectors, both survey and case study evidence point to the negative effects of unpaid overtime, taking work home or feeling exhausted after work.

Technology - in form of hardware (smartphones, laptops) and software (email, social media, internet and intranets) - is frequently identified as a cause of work elasticity and work-life interference. Whilst this is undoubtedly true, particularly for professional, technical and managerial employees, it can be a partial picture in other ways. As McDonald and Thompson (2016) argue, work-life boundary changes are being driven from above and below. There is evidence of employers using technology to extend work and social media to 'profile' employee suitability for and performance in jobs. However, employees are also purposeful agents who bring more of their personal selves into the workplace, as well as their smartphones and devices to manage their nonwork lives. Such activities open up new spaces for worker misbehaviour and managerial regulation.

\section{Dis/engagement}

We have already noted survey and other evidence of relatively high levels of satisfaction or other measures of work attachment. Yet the problem of employee engagement remains something that employers appear to be obsessed with, with many companies undertaking annual surveys of their staff. Practitioner and academic literatures see engagement as the critical factor in increasing productivity and achieving other positive work outcomes (Dromey 2016). It is not difficult to be somewhat sceptical of the concept. Across the practitioner and academic literatures engagement has emerged as a kind of umbrella term that lacks precision and clear differentiation from motivation, commitment or organisational citizenship behaviour, spanning employee attitudes and behaviours as well as the organisational practices (Rayton et al 2012:3).

Despite these confusions there are two reasons for taking engagement seriously as a window into work trends. First, it focuses attention on the kind of behaviours that employers regard as central to discretionary effort. Second, there is an emergent body of survey evidence that tells us quite a lot 
about employee attitudes to their job and organisation. The news is not good for employers. As the most in-depth overview of the current evidence states, 'The UK has an employee engagement deficit. Survey after survey indicates that only one third of UK workers say they are engaged' (Rayton et al 2012: ii). Nor is this confined to the UK. Two global employee surveys found very low levels of engagement. In the first (Towers Watson 2012), 43\% were either disengaged or detached, with 35\% highly engaged and $22 \%$ feeling unsupported by management. Australian and UK figures were below the global average. An even more pessimistic picture is reported in the second (Gallup 2012) with only $13 \%$ of employees engaged at work, $62 \%$ not engaged and $24 \%$ actively disengaged. Here, because of the wider range of countries, Australian and UK levels were higher than the average at $24 \%$ and $17 \%$ engaged, though still dwarfed by those reporting neutrality or disengagement. National surveys in both countries produce similarly negative results. In Australia, a survey of 3361 employees produced an engagement score of $-23 \%$, with an average discretionary effort score of 5.8 out of 10 (Engaged Marketing 2015).

Potential explanations for this trend can be found by focusing on two key 'enablers' widely identified in the literature - voice and integrity (Rayton et al 2012). Surveys are consistent in identifying the significance of employers listening to the views of workers and communicating honestly with them, and the scepticism of employees about whether this takes place in any meaningful way (Dromey 2016). The decline of unions as a collective voice mechanism in most post-industrial economies has exacerbated this problem. Integrity refers to the extent to which the values of the organisation are reflected in everyday practices. Whilst the rhetoric-reality gap is a perpetual refrain of critical academic research, again there are plausible 'external' and 'internal' reasons why this problem may be increasing. With respect to the former, financialization has undermined the conditions for stability and investment by non-financial corporations, leading to employers not being able to 'keep their side of the bargain' (Thompson 2003) and 'breaches of trust' with stakeholders (Appelbaum, Batt and Clark 2013). In this context, high performance from employees is more likely to be the result of compliance deriving from the disciplinary effects of market conditions than engagement 
and discretionary effort (McGovern et al 2007). Within large organisations, the tendency for HR initiatives to be framed as values-led organisations has made discrepancies with actual corporate practices more visible (Cushen and Thompson 2012). Amongst the markers of the subsequent disengagement are declining trust levels (CIPD 2012) and the growth of organisational cynicism (Naus et al 2007) or 'employee silence' (Donaghey et al 2011). Whether disengagement is being translated into more active dissent is beyond our scope, though there is emergent evidence of the role of blogs and social media as new sources of employee voice in general (Richards and Kosmala 2013) and in disputes (Moore and Taylor and 2016).

\section{Conclusions}

The meanings of work are experienced at individual level, but determined largely by structural changes at corporate, labour market and labour process level. We have sketched out some mediumterm and emerging trends concerning some of those changes. There are a number of overlapping themes that have significance for the kinds of research questions we pursue. This article makes a particular contribution by drawing attention to the importance of the intersection of labour market and labour process factors in configuring work content and experience, and the need to consider trajectories of change within and across occupations over time. For example, insecurity is not just a property of 'non-standard' workers and derives increasingly from treatment at as well as access to work. Other developments in contemporary working also change 'standard' working such that features like distanced working or variable hours may now be a feature of both types (Cappelli 2013). Cappelli promotes the analytical purchase of a greater focus on who controls work, rather than contractual arrangements, in differentiating more or less externalised work - prioritising labour process rather than labour market distinctions. Such trends open up research questions about the shared aspirations and experience of categories of workers traditionally demarcated as 'insiders' and 'outsiders' and how they impact on each other. Beyond the obvious point that we need to know more about how any trends are playing out across countries, sectors, industries, firms, occupations 
and demographics, researchers need to be careful about how trends are translated into theoretical constructs. So, for instance, varied forms of precariousness for some workers too easily becomes 'the precariat' which appears to encompass the majority of the working population.

Further disruption of traditional boundaries is emerging through the 'gig economy' or crowdsourcing, in which digital platforms (such as Amazon's Mechanical Turk or Uber) act as a form of 'internalized offshoring' (Silverman 2014) to allocate work and provide services. Whilst this is clearly an impetus to the further growth of (often bogus) self-employment, at this stage there is little academic research on the consequences. What we do have is a new positive flexibility narrative and some typically inflated claims concerning scope, coverage and content, with promises of 'freedom from institutionalised hierarchies, the autonomy to determine what work you do and how' (Cefkin, Anya and Moore 2014:4). The World Bank (2015) recently estimated that there were 48 million people registered on such platforms, though only around $10 \%$ were considered to be active. Whilst such markets may create opportunities for expert labour in developing countries, but they have the potential to impact negatively on the terms and conditions of workers in advanced economies. On many of the largest platforms, much of the content consists of microtasks that require minimal skill, training and rewards (Silverman 2014).

Our analysis of trends, is, of course, impacted by the predominant focus on the UK and Australia. Despite what appear to be common themes raised in a broad range of critical scholarship, we need to recognise that the UK sits among the top group of countries on most discrete job quality components and on job quality indices (for example, Leschke and Watt 2008). While Australia does not feature in European comparison tables, other data suggests it is not a significant outlier. Of equal importance, not all work - or all aspects of work - are subject in the same way to the stresses and pressures we have outlined. Put another way, though work intensity and elasticity, precariousness and performance pressures, are all increasing, much work in both countries, while 
not always engaging, is neither perceived as insecure nor subject to excessive work pressures or monitoring.

Moving to more subjective measures, the impact of social conditioning on reported job satisfaction makes it a poor proxy for job quality, and notwithstanding that 'the empirical distribution of job satisfaction across countries does not seem congruent with anything we know about the conditions of work and employment across the world' (Munoz de Bustillo 2011:451), job satisfaction does tell us something about what we want - and get - from work. We need to understand both job quality and job satisfaction as reflections of how control, conflict and consent play out in the work domain, crucially, because neither are "... socially determined by a set of managerially prescribed job characteristics" but are arrived at by workers themselves, individually and collectively (Brown, Charlwood and Spencer 2012:1013). It simply isn't true that, as recent post-work theorists claim, that, 'For the vast majority of people, work offers no meaning, fulfilment or redemption' (Srnicek and Williams 2015, p. 117). Survey and qualitative research indicates a complex mixture of positive attachments to work and work identity, but increasing concerns about issues such as insecurity, recognition, under-employment, work pressures and unfair rewards. In other words, there is for many a growing divergence between what work demands from us and we demand from work, between the objective and subjective.

Reflecting on the contemporary meaning of work raises issues for research and for policy intervention. The growing academic literature on job quality, primarily drawing on large national surveys, provides an important resource for addressing some the questions that we raise here. While job quality indices are attractive for comparative research in particular, there are risks that indices lose sight of the multidimensionality of work and work practice. Moreover, this work remains constrained by widely accepted data limitations. Qualitative (and often single) case studies address some of these issues and are far better at locating work practice in context, but carry their own limitations and are often poorly validated within the sector, industry or institutional environments. 
Both qualitative and quantitative work is needed to address these lacunae: the former to better understand issues of disposition, outlook and habitus (Hebson 2009), the latter to ground this understanding in a broader context and to underpin more nuanced comparisons. We also need better longitudinal analysis and a more sophisticated sense of timing and the momentum of change, given that some of the developments we have outlined emerged in the late 70 s and early 80 s, while others are more recent.

This takes us to the policy space. The costs imposed by particular developments at work - increasing insecurity, declining real wages, less effective voice - on individuals and societies is now recognised in discourse at supra-national and national level in debates around decent or better work. Opening up a debate around 'good' and 'bad' jobs (Warhurst et al 2012) has been useful in drawing attention particularly to those at the harshest edge of the labour market. Progressing this debate, as we have argued here, requires a more nuanced understanding of the positive elements of 'bad' jobs and the more negative elements of 'good' jobs. For example, care workers often report high intrinsic satisfaction alongside low pay, while professionals in ostensibly 'good' jobs report increasingly long hours and intensified work. A more nuanced account opens up the debate for policy levers that can address both. Reflecting other historical time periods, there has been at least some post GFC recognition of the limits to employer strategies that disproportionately shift risk and immiserate labour. Labour movement activism and regulation, hard and soft, are the core processes of redress for at least some of the power imbalances at work, and debates on fair work in Australia and in (parts of) the UK (Fair Work Convention 2016) provide an arena in which policymakers, unions, employers and other key stakeholders can discuss what we want from work and what it wants from us. Researchers have a key role to play in ensuring that these processes draw on rigorous, robust and relevant evidence, making it of crucial importance that we ask the right questions and answer them appropriately, distinguishing between patterns and trends and recognising both novelty and continuity. 


\section{References}

Angrave D and Charlwood A (2015) What is the relationship between long working hours, overemployment, under-employment and the subjective well-being of workers? Longitudinal evidence from the UK. Human Relations 68(9): 1491-1515.

Appelbaum E, Batt R and Clark I (2013) Implications of financial capitalism for employment relations research: evidence from breach of trust and implicit contracts in private equity buyouts. British Journal of Industrial Relations 51(3): 498-518.

BIS (2014) Work Life Balance Employer Survey. Department of Business and Skills, London: HMSO.

Bolton S and Houlihan M (eds) (2009) Work Matters: Critical Reflections on Contemporary Work. Basingstoke: Palgrave.

Brown M and Heywood J S (2005) Performance Appraisal Systems: Determinants and Change. British Journal of Industrial Relations 43(4): 659-679.

Brown A, Charlwood A and Spencer DA (2012) Not all that it might seem: why job satisfaction is worth studying despite it being a poor summary measure of job quality. Work, Employment \& Society 26(6): 1007-1018.

Buchanan J, Scott L, Yu S, Schutz J and Jakubauskas M 2010 'Skills Demand and Utilisation: An International Review of Approaches to Measurement and Policy Development', OECD Local Economic and Employment Development (LEED) Working Papers, 2010/4

Budworth MH and Mann SL (2011) Performance Management: Where do we go from here? Human Resource Management Review 21: 81-84.

Carre' F, Findlay P, Tilly C and Warhurst C (2012) Job quality: scenarios, analysis and interventions. In: Warhurst C, Findlay P, Tilly C and Carre' F (eds) Are Bad jobs inevitable? 
London: Palgrave.

Carter B, Danford A, Howcroft D, Richardson H, Smith A and Taylor P (2011) 'All they lack is a chain': lean and the new performance management in the British civil service. New Technology, Work and Employment, 26(2): 83-97.

Cappelli P and Keller J (2013) Classifying Work in the New Economy. Academy of Management Review 38(4): 575-596

Cefkin M, Anya O and Moore R (2014) A Perfect Storm? Reimagining Work in the Era of the End of the Job. Ethnographic Praxis in Industry Conference Proceedings 3-19. doi:10.1111/15598918.01002.

CIPD (2012) Where has all the trust gone? London: CIPD.

CIPD (2015) Reward Management Survey 2014-15. London: CIPD.

CIPD (2014) CIPD/Halogen Software Employee Outlook. London: CIPD.

Conley H (2012) Guy Standing, The Precariat: The New Dangerous Class. Work, Employment \& Society, 26(4): 686-688.

Cushen J and Thompson P (2012). Doing the right thing? HRM and the angry knowledge worker. New Technology, Work and Employment 27(2): 79-92.

Dekker F and van der Veen R (2015), Modern working life: A blurring of the boundaries between secondary and primary labour markets? Economic and Industrial Democracy 0143831X14563946, first published on January 21, 2015.

Doherty M (2009) When the Working Day is Through: The End Of Work as Identity? Work, Employment and Society 23(1): 84-101. 
Donaghey J, Cullinane N, Dundon T and Wilkinson A (2011) Reconceptualising employee silence problems and prognosis. Work, Employment \& Society 25(1): 51-67.

Dromey, J (2016) Involvement and productivity: The Missing Piece of the Puzzle? London: IPA. Engaged Marketing (2015) The State of Employee Engagement in Australia. Brisbane: Engaged Marketing.

Fair Work Commission (2016) Australian Workplace Relations Study First Findings

Report 5 February 2016. Available at: https://www.fwc.gov.au/resources/research/australianworkplace-relations-study/first-findings-report (accessed 12 March 2016).

Fair Work Convention (2016) Fair Work Framework 2016. Available at http://www.fairworkconvention.scot/framework/FairWorkConventionFrameworkFull.pdf. Felstead A, Gallie D, Green F and Inanc H (2013) Work Intensification in Britain: First Findings from the Skills and Employment Survey 2012, London: Centre for Learning and Life Chances in Knowledge Economies and Societies, Institute of Education.

Findlay P and McKinlay A (2003) Surveillance, electronic communications technologies and regulation. Industrial Relations Journal 34(4): 305-318.

Gallie D, Felstead A and Inanc H (2016) The hidden face of job insecurity. Work, Employment and Society. Published online before print January 29, 2016, doi: 10.1177/0950017015624399

Gallup (2012) State of the Global Workplace. http://www.gallup.com/poll/165269/worldwideemployees-engaged-work.aspx Accessed 13 April 2016.

Green F (2006) Demanding work: The paradox of job quality in the affluent economy. Princeton University Press. 
Hall R (2006) Temporary agency work and HRM in Australia: Cooperation, specialisation and satisfaction for the good of all? Personnel Review 35(2): 158 - 174.

Hebson G (2009) Renewing Class Analysis in Studies of the Workplace: A Comparison of Workingclass and Middle-class Women's Aspirations and Identities. Sociology 43(1): 27-44.

Hebson G, Rubery J and Grimshaw D (2015) Rethinking job satisfaction in care work: looking beyond the care debates. Work, Employment and Society 29(2): 314-330.

Hochschild A (1997) The time bind: When work becomes home and home becomes work. New Yord: Horton Metropolitan Books.

Jacobs K (2016), CIFF's fresh approach to performance management. HR Magazine, 17 March 2016,

Kalleberg A (2009) Precarious Work, Insecure Workers: Employment Relations in Transition.

American Sociological Review 74: 1-22.

Knox A (2015) The Temporary Agency Work Industry and its Regulatory Environment: Evidence from Australia. In Fu H (ed) Temporary Agency Work and Globalisation: Beyond Flexibility and Inequality, Huiyan Fu, Farnham: Gower Publishing Limited, 95-125.

Laaser K (2016), 'If you are having a go at me, I am going to have a go at you': the changing nature of social relationships of bank work under performance management. Work, Employment and Society Epub ahead of print 12 January 2016. DOI: 10.1177/0950017015617686.

Leschke J and Watt A (2008) 'Job Quality in Europe. European Trade Union Institute Working Paper No 2008.07. Bruxelles: ETUI.

Mason, P. (2015) PostCapitalism: A Guide to our Future. London: Allen Lane.

McCann L, Hassard JS, Granter E and Hyde, PJ (2015) Casting the lean spell: The promotion, dilution and erosion of lean management in the NHS. Human Relations 68(10): 1557-1577. 
McDonald P and Thompson P (2016) Social Media(tion) and the Reshaping of Public/Private Boundaries in Employment Relations. International Journal of Management Reviews 18(1): 69-84.

McGovern P, Hill S, Mills C and White M (2007) Market, class, and employment. Oxford: Oxford University Press.

McKenna S, Richardson J and Manroop L (2011) Alternative paradigms and the study and practice of performance management and evaluation. Human Resource Management Review 21: 148-157.

Moore S and Taylor P (2016) 'We planned a dispute by Blackberry': The impact of restrictions on the use of social media in industrial action in the light of the British Airways dispute - 2009-11. Industrial Law Journal, On-line first DOI: 10.1093/indlaw/dww011 (accessed 16 June 2016). Munoz de Bustillo R, Fernandez-Macıas E, Fernando E and Anton JI (2011) E pluribus unum? A critical survey of job quality indicators. Socio-Economic Review 9: 447-475.

Nankervis AR, Stanton P and Foley P (2012). Exploring the Rhetoric and Reality of Performance Management Systems and Organisational Effectiveness - Evidence from Australia. Research and Practice in Human Resource Management 20(1): 40-56.

Naus F, van Iterson A and Roe R (2007) Organizational cynicism: Extending the exit, voice, loyalty, and neglect model of employees' responses to adverse conditions in the workplace. Human Relations 60: 683-718.

Newcombe T (2012) Workplace appraisals are becoming a "tick box" exercise, say UK workers HRmagazine 14 November 2012.

OECD (2015) In It Together: Why Less Inequality Benefits All. Paris: OECD.

ONS (2014) Self-employed workers in the UK - 2014. London: Office for National Statistics. 
Philpott J (2012) The rise in self-employment. London: Chartered Institute of Personnel and Development.

Pocock B, Skinner N and Williams P (2012) Time Bomb: Work, rest and play in Australia today. UNSW Press.

Rayton B, Dodge T and D'Aneleze G (2012) The Evidence: Employee Engagement Task Force. London: Engage for Success.

Richards J and Kosmala K (2013) 'In the End, You Can Only Slag People Off for so Long': Employee Cynicism through Work Blogging. New Technology, Work and Employment 28(1): 66-77.

Rock D and Jones B (2015) 'Why more and more companies are ditching performance ratings', Harvard Business Review, 8 September.

Skinner N and Pocock B (2011) Flexibility and work-life interference in Australia. Journal of Industrial Relations 53(1): 65-82.

Silverman J (2014) The crowdsourcing scam. The Baffler 26: 106-117.

Smith C and Liu M (2016) In Search of the Labour Process in China. In Smith L M and Smith C (eds.) China at Work. Houndmills: Palgrave Press.

Srnicek, N. and Williams, A. (2015) Inventing the future: Postcapitalism and a world without work. London: Verso Books.

Standing G (2011). The precariat: The new dangerous class. London: Bloomsbury Academic. Streeck W (2008) Flexible Markets, Stable Societies? MPIfG Working Paper 08/6. Available at http://www.mpifg.de/pu/workpap/wp08-6.pdf

Taylor P (2013) Performance Management and the New Workplace Tyranny. A Report for the Scottish Trade Union Congress. Glasgow: University of Strathclyde. 
Thompson P (2003) Disconnected capitalism: or why employers can't keep their side of the bargain. Work, Employment and Society 17(2): 359-378.

Thompson P (2013) Financialization and the workplace: extending and applying the disconnected capitalism thesis. Work, Employment and Society 27(3):472-488.

Towers Watson (2012) Global Workforce Study https://www.towerswatson.com/Insights/ICTypes/Survey-Research-Results/2012/07/2012-Towers-Watson-Global-Workforce-Study Accessed 10 November 2015.

Van Wanrooy B, Bewley H, Bryson A, et al. (2013) Employment Relations in the Shadow of

Recession: Findings from the 2011 Workplace Employment Relations Study. Houndmills:

Palgrave Press.

Warhurst C, Carre F, Findlay P and Tilly C (2012) Are Bad Jobs Inevitable? Trends, Determinants and Responses to Job Quality in the Twenty-First Century. London: Palgrave Macmillan.

World Bank (2015) The Global Opportunity in Online Outsourcing, The World Bank: Washington.

Wright J and Sissons P (2012) The Skills Dilemma: Skills Under-utilisation and Low-Waged Work. London: The Work Foundation.

Endnotes

\footnotetext{
' WERS is the established UK survey (van Wanrooy et al 2013); AWRS covers some of the same ground, but is undertaken by a regulatory agency - The Fair Work Commission (2015) - and ints focus on regulatory compliance contains less of the detail and richness of the WERS data. Other national surveys referred to are specifically referenced.
} 